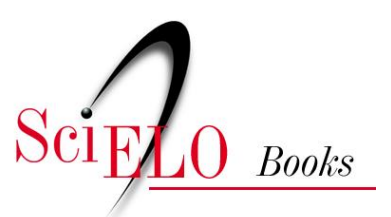

\title{
Ordem Beryciformes
}

\author{
Ana Cristina Teixeira Bonecker \\ Claudia Akemi Pereira Namiki \\ Márcia Salustiano de Castro \\ Paula Nepomuceno Campos
}

\section{SciELO Books / SciELO Livros / SciELO Libros}

BONECKER, ACT., et al. Ordem Beryciformes. In Catalogo dos estágios iniciais de desenvolvimento dos peixes da bacia de Campos [online]. Curitiba: Sociedade Brasileira de Zoologia, 2014, pp. 165-168. Zoologia: guias e manuais de identificação series. ISBN 978-85-98203-10-2.

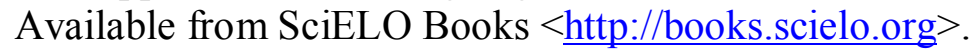

\section{(1)(9)(2)}

All the contents of this chapter, except where otherwise noted, is licensed under a Creative Commons Attribution-Non Commercial-ShareAlike 3.0 Unported.

Todo o conteúdo deste capítulo, exceto quando houver ressalva, é publicado sob a licença Creative Commons Atribuição Uso Não Comercial - Partilha nos Mesmos Termos 3.0 Não adaptada.

Todo el contenido de este capítulo, excepto donde se indique lo contrario, está bajo licencia de la licencia Creative Commons Reconocimento-NoComercial-CompartirIgual 3.0 Unported. 


\section{ORDEM BERYCIFORMES}

A ordem Beryciformes é composta por sete famílias e 144 espécies. As espécies são caracterizadas pela presença do osso orbitoesfenoide e possuem mais de cinco raios nas nadadeiras pélvicas. As larvas assemelham-se as larvas da ordem Perciformes, com a cabeça proeminente e espinhos nas nadadeiras.

Nesse estudo a ordem Beryciformes é representada pela família Holocentridae. 


\section{Família Holocentridae}

A família Holocentridae é composta por oito gêneros com aproximadamente 78 espécies. Os representantes normalmente são associados a recifes. A maioria das espécies ocorre entre a linha da costa e a isóbata de $100 \mathrm{~m}$. Esta família está dividida em duas subfamílias Holocentrinae e Myripristinae. As larvas de Holocentrinae são caracterizadas por um espinho rostral simples e desenvolvimento tardio da nadadeira pélvica. As larvas de Myripristinae são caracterizadas por um espinho rostral bifurcado e desenvolvimento da nadadeira pélvica por volta dos $3,5 \mathrm{~mm}$. As famílias Peristidae e Triglidae também possuem espinhos no rostro, mas esses são normalmente bilaterais, o que as separa de Holocentridae. Os holocentrídeos apresentam uma forma de transição pelágica, um estágio de pré-assentamento denominado estágio rhynchichthys, onde os raios e espinhos das nadadeiras estão completamente formados, mas o espinho rostral permanece. Algumas espécies também possuem uma fase pré-juvenil denominada estágio meeki que permanece pelágica, mas já está pronta para assentar no fundo. Nesse estágio há perda dos espinhos da cabeça.

No Brasil já foram identificadas oito espécies nas fases de larva e adulto. Nesse estudo são contempladas as espécies Holocentrus sp. e Sargocentron bullisi. 


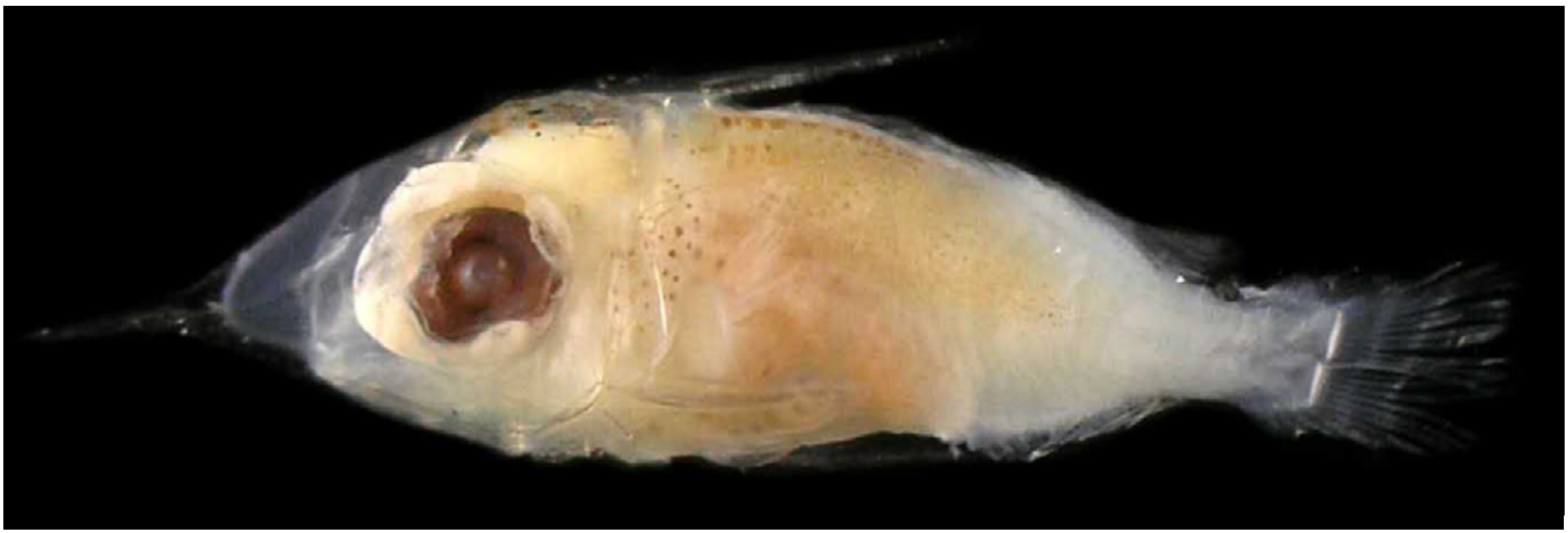

Figura 96: Holocentrus sp. DZUFRJ 1220; Flexão; CP 6,0 mm.

\section{Holocentrus sp.}

As larvas da família Holocentridae são separadas principalmente pela forma e pelo tamanho dos espinhos da cabeça, do pré-opérculo e do rostro. Os representantes do gênero Holocentrus possuem corpo e cabeça altos e pedúnculo caudal estreito. Apresentam pigmentação intensa no peritôneo. Os espinhos da cabeça, do pré-opérculo e do rostro possuem tamanho intermediário, entre as larvas de Sargocentron e Myripristinae. O espinho rostral é simples e os espinhos da cabeça e do pré-opéculo alcançam a metade do corpo. Nadadeira dorsal com 11 espinhos; nadadeira anal com 10 raios e nadadeira dorsal com 14-16 raios. O número total de miômeros varia entre 26 e 27. No Brasil foram registradas as espécies Holocentrus adscensionis (Osbeck, 1765) e Holocentrus rufus (Walbaum, 1792).

Tamanho: flexão 6,0-6,5 mm.

Habitat: todas as espécies de Holocentrus registradas na literatura são marinhas e vivem associadas a formações coralinas. São demersais e a maioria ocorre em águas rasas.

\section{Georreferencimento}

\begin{tabular}{|c|c|c|c|c|c|c|c|c|}
\hline DZUFR & Latitude (S) & Longitude (W) & Data & $\begin{array}{c}\text { Tipo de } \\
\text { arrasto }\end{array}$ & $\begin{array}{c}\text { Profundidade } \\
\text { de coleta }\end{array}$ & Rede & $\begin{array}{c}\text { Malha } \\
\text { ( } \boldsymbol{\mu m})\end{array}$ & $\begin{array}{c}\mathbf{N}^{\circ} \text {. de } \\
\text { inds. }\end{array}$ \\
\hline 1220 & $22^{\circ} 02^{\prime} 30,0^{\prime \prime}$ & $039^{\circ} 49^{\prime} 41,2^{\prime \prime}$ & $12 / 05 / 2002$ & oblíquo & $1.000 \mathrm{~m}$ & cilíndrico-cônica & 500 & 1 \\
\hline 7516 & $2^{\circ} 1^{\circ} 3^{\prime} 10,4^{\prime \prime}$ & $039^{\circ} 45^{\prime} 499^{\prime \prime}$ & $10 / 10 / 2001$ & oblíquo & $1.000 \mathrm{~m}$ & cilíndrico-cônica & 500 & 1 \\
\hline
\end{tabular}

Referências: Leis \& Rennis, 1983; Tyler et al., 1993; Lyczkowski-Shultz et al., 2000; Bonecker et al., 2006; Fahay, 2007. 


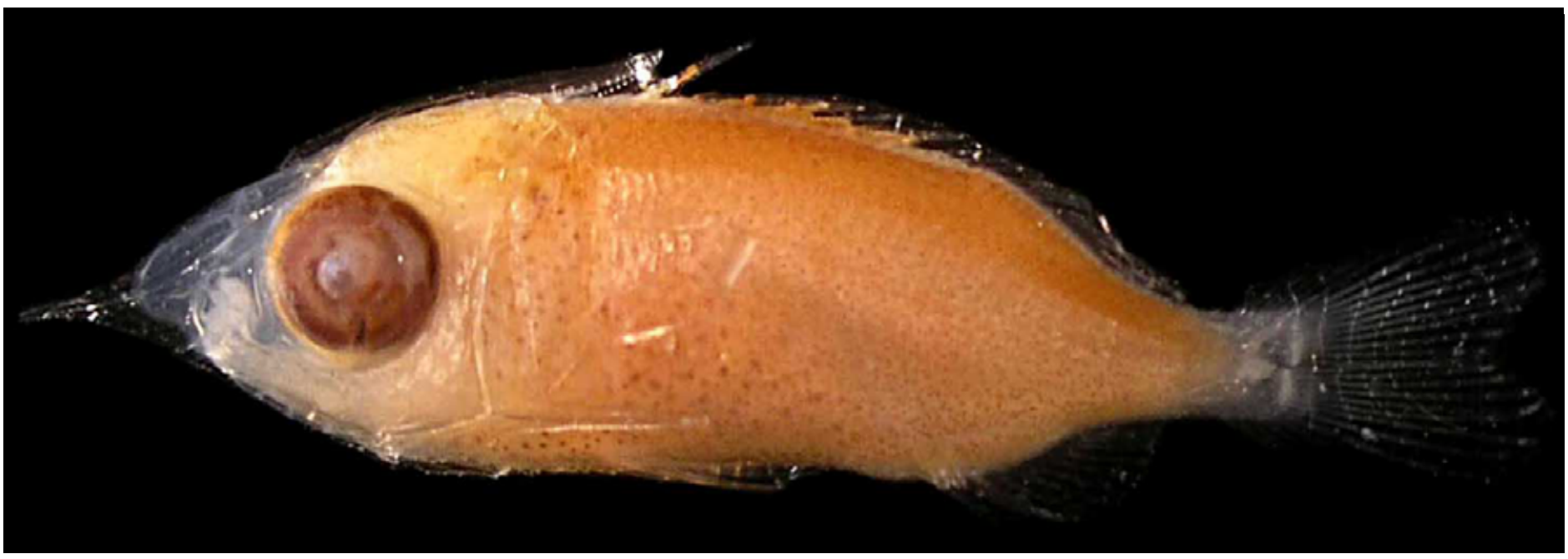

Figura 97: Sargocentron bullisi. DZUFRJ 7515; Pós-flexão; CP 11,0 mm.

\section{Sargocentron bullisi (Woods, 1955)}

Os espinhos da cabeça, do pré-opérculo e do rostro são longos. Os espinhos do pré-opérculo alcançam os últimos raios da nadadeira dorsal e anal. Apresenta pigmentação intensa no peritônio e alguns melanóforos no pedúnculo caudal e na cabeça. Nadadeira dorsal com 11 espinhos; nadadeira anal com oito raios e nadadeira dorsal com 11-12 raios. O número total de miômeros varia entre 26 e 27.

Tamanho: pós-flexão 11,0 mm.

Habitat: espécie associada a formações coralinas, ocorre entre 33 e 110 $\mathrm{m}$ de profundidade.

Nome vulgar: Jaguareçá listrado.

\section{Georreferencimento}

\begin{tabular}{|c|c|c|c|c|c|c|c|c|}
\hline DZUFRJ & Latitude (S) & Longitude (W) & Data & $\begin{array}{c}\text { Tipo de } \\
\text { arrasto }\end{array}$ & $\begin{array}{c}\text { Profundidade } \\
\text { de coleta }\end{array}$ & Rede & $\begin{array}{c}\text { Malha } \\
(\boldsymbol{\mu m})\end{array}$ & $\begin{array}{c}\mathbf{N}^{\circ} \text {. de } \\
\text { inds. }\end{array}$ \\
\hline 7515 & $21^{\circ} 54^{\prime} 36,5^{\prime \prime}$ & $039^{\circ} 45^{\prime} 20,0^{\prime \prime}$ & $09 / 10 / 2001$ & oblíquo & $1.000 \mathrm{~m}$ & cilíndrico-cônica & 500 & 1 \\
\hline
\end{tabular}

Referências: Leis \& Rennis, 1983; Lyczkowski-Shultz et al., 2000; Bonecker et al., 2006; Fahay, 2007. 